Rev. Ter. Ocup. Univ. São Paulo, v. 17, n. 2, p. 48-56, maio/ago. 2006.

\title{
Perfil dos freqüentadores da casa de convivência e centro de serviços Associação Minha Rua Minha Casa entre 2002 e 2003
}

\author{
Profile of users of the center of services Associação \\ Minha Rua Minha Casa between 2002 and 2003
}

\author{
Debora Galvani ${ }^{1}$, Denise Dias Barros ${ }^{2}$, Miki Takao Sato ${ }^{3}$, Tiy de \\ Albuquerque Maranhão Reis ${ }^{4}$, Marta Carvalho de Almeida ${ }^{5}$
}

\begin{abstract}
GAlVANI, D.; BARROS, D. D.; SATO, M. T.; REIS, T. A. M.; ALMEIDA, M. C. Perfil dos freqüentadores da casa de convivência e centro de serviços Associação Minha Rua Minha Casa entre 2002 e 2003. Rev. Ter. Ocup. Univ. São Paulo, v. 17, n. 2, p. 48-56, maio/ago. 2006.

RESUMO: São discutidos os resultados de pesquisa realizada entre 2002 e 2003 na casa de convivência e centro de serviços Associação Minha Rua Minha Casa (AMRMC), local de atendimento a população adulta em situação de rua na cidade de São Paulo. A partir de entrevistas abertas e semi-estruturadas, a pesquisa buscou compreender o perfil de seus freqüentadores quanto às trajetórias cotidianas, as características da circulação na cidade de São Paulo e as redes de serviços e apoios utilizados. Os dados obtidos são semelhantes aos dados dos censos realizados pela SAS/FIPE nos últimos anos sobre esta população na cidade de São Paulo, porém revelam diferentes trajetórias pessoais que conferem a AMRMC possibilidade de criar algum espaço de pertencimento. O conhecimento aprofundado de trajetórias pessoais é de fundamental importância para a criação de projetos pessoais que considerem o contexto e história da pessoa atendida. Procura-se trabalhar nesta perspectiva sempre em diálogo com usuários e instituição, compreendendo que a pesquisa é mais um instrumento no processo de mútuo conhecimento. A gravidade da situação e as necessidades da população impõem desafios a serem superados a partir de respostas da própria população.
\end{abstract}

DESCRITORES: Vulnerabilidade. Grupo social. Terapia Ocupacional. Sem-teto. Abrigo.

1 Terapeuta Ocupacional do Departamento de Fonoaudiologia, Fisioterapia, Terapia Ocupacional da Faculdade de Medicina da Universidade de São Paulo. Pesquisadora do núcleo USP/UFSCar Projeto Metuia.

2 Professora Doutora do Departamento de Fonoaudiologia, Fisioterapia, Terapia Ocupacional da Faculdade de Medicina da Universidade de São Paulo. Doutora em Sociologia pela USP. Coordenadora do núcleo USP/UFSCar do Projeto Metuia.

3 Bolsista COSEAS (2002-2004) pelo núcleo USP/UFSCar do Projeto Metuia. Estudante do Curso de Terapia Ocupacional do Departamento de Fonoaudiologia, Fisioterapia, Terapia Ocupacional da Faculdade de Medicina da Universidade de São Paulo.

4 Terapeuta Ocupacional da Associação Minha Rua Minha Casa. Pesquisadora do núcleo USP/UFSCar Projeto Metuia.

5 Professora Doutora do Departamento de Fonoaudiologia, Fisioterapia, Terapia Ocupacional da Faculdade de Medicina da Universidade de São Paulo.

Endereço para correspondência: Departamento de Fonoaudiologia, Fisioterapia, Terapia Ocupacional da Faculdade de Medicina da Universidade de São Paulo. Rua Cipotânea, 51. CEP: 5360-160. São Paulo, SP. 


\section{INTRODUÇÃO}

$\mathrm{T}$ Trata-se de discutir o perfil dos associados da Associação Minha Rua Minha Casa (AMRMC) a partir dos resultados de pesquisa realizada entre 2002 e 2003. AAMRMC é uma casa de convivência e centro de serviços para adultos em situação de rua, integrando, portanto, a rede assistencial do município de São Paulo. O estudo foi realizado por pesquisadores do Projeto Metuia, núcleo interinstitucional de estudos, formação e ações pela cidadania de crianças jovens e adultos em processos de ruptura das redes sociais de suporte, que desde 2000 estabeleceu parceria com esta instituição desenvolvendo atividades de assistência, ensino e pesquisa.

\section{DESCRIÇÃODAMETODOLOGIA}

Essa pesquisa foi elaborada como resposta à demanda da equipe da AMRMC para que, ao se produzir uma avaliação do perfil de seus freqüentadores, pudesse rever as propostas assistenciais em curso e para favorecer a reflexão sobre suas ações.

AAMRMC oferece acolhimento diurno entre $8 \mathrm{~h}$ e $18 \mathrm{~h}$ de segunda a sábado, disponibilizando alguns serviços abertos aos usuários que chegarem no dia e outros restritos aos associados.

Diariamente acontecem no Glicério atividades de lazer, cultura, trabalho, cuidados pessoais, atendimento psicológico e prevenção do uso de álcool e de drogas. Em clima de mutirão entre funcionários, voluntários e povo da rua, são preparadas refeições, escrevem cartas, costuramse as roupas maltratadas, faz-se a barba e cabelo, o que propicia o estabelecimento de vínculos, estimula a quebra de relações de dependência e a recuperação de sua autonomia (AMRMC, 2005).

A AMRMC distingue os freqüentadores pelo grau de vinculação e comprometimento que estabelecem com a instituição, são eles: associados, usuários participantes e usuários. Os associados constituem o grupo de maior vinculação com a instituição, pois se comprometem com a participação em tarefas diárias e na assembléia geral, tendo em contrapartida benefícios como café da manhã e almoço, armários próprios permanentes, crédito no brechó, podendo freqüientar o espaço entre $8 \mathrm{~h}$ e $18 \mathrm{~h}$ além daqueles abertos a todos os presentes. Os usuários participantes têm um vínculo e obrigações menores que os associados, mas têm acesso à AMRMC por período de $8 \mathrm{~h}$ diárias. A participação dos usuários é flexível e variada, mas podem usufruir de parte dos serviços e apenas no período da tarde. Qualquer usuário pode utilizar o espaço na parte da tarde tanto para descansar, ler, proteger-se da exposição da rua, alimentar-se, escrever cartas, realizar higiene pessoal quanto participar de algum programa que esteja sendo desenvolvido.

Para este estudo, priorizou-se o grupo de associados por ser composto por pessoas com maior vinculação com a entidade e os pesquisadores participaram de vários momentos da dinâmica institucional, facilitando a aproximação com este grupo. A pesquisa foi apresentada e aprovada pela coordenação e, posteriormente pela assembléia de associados. Durante a assembléia foi explicada tanto seus objetivos como sua metodologia, explicitando que o convite era para todo associado que se dispusesse a participar da pesquisa. No momento de marcar as entrevistas o convite era refeito e se a pessoa concordasse, marcavam-se os encontros. Procedia-se à leitura do termo de consentimento livre e esclarecido e à solicitação de sua assinatura.

Partiu-se de um universo de 54 associados, segundo listagem fornecida pela AMRMC referente ao período compreendido entre junho de 2002 e junho de 2003. Entre esses, 11 não foram localizados no período em que se desenvolveu o estudo, nove dos quais foram desligadas, pois não mantinham mais relação com a instituição. Considera-se então que o universo total de pesquisa como sendo de 43 pessoas. Desses, 35 foram entrevistados, pois oito não quiseram participar.

A partir de um roteiro de perguntas com entrevistas abertas e semi-estruturadas, buscou-se definir as trajetórias cotidianas, a história de seus deslocamentos, as características da circulação na cidade de São Paulo e a apreensão das redes de serviços e de apoios utilizados. Além disso, pretendeu-se conhecer como constroem suas redes sociais e obter informações sobre formação, qualificação profissional, trabalho, formas de geração de renda e tipos de moradia.

\section{AMRMC: breve histórico e organização}

A AMRMC foi criada em $1994 \mathrm{em}$ parceria com membros do Pensamento Nacional das Bases Empresariais (PNBE) e Organização de Auxílio Fraterno (OAF) Organização não-governamental (ONG) vinculada a Igreja Católica que atua desde 1955 junto à população em situação de rua, sendo a AMRMC, desdobramento deste trabalho que já se realizava. O trabalho da OAF com esta população inspirou a formulação do projeto das casas de convivência sendo estabelecidos os primeiros convênios com a Prefeitura no final da década de 80 (VIEIRA et al., 2004, p.141). Alguns anos depois de sua criação, a AMRMC 
conveniou-se com a Prefeitura do Município de São Paulo (PMSP) e passou a integrar a rede de serviços disponibilizados pela Secretaria de Assistência Social (SAS) para essa população.

As casas de convivência são caracterizadas por oferecer acesso a alguns serviços como higienização, alimentação, escrita de correspondência, retirada de documentação e encaminhamentos a programas da Prefeitura além de outras propostas, que variam de acordo com a instituição, segundo Varanda (2003, p. 10) de promoção de programas sociais de caráter educativo, culturais, religiosos, recreativos ou terapêuticos. Ainda segundo o autor, os projetos de referência da OAF são caracterizados por uma metodologia de trabalho que propõe o protagonismo da pessoa, privilegiando-se "trabalhar com e não para o morador de rua" (VARANDA, 2003, p. 3).

A AMRMC entende a população atendida como "pessoas e cidadãos com direitos e deveres: direito à vida, a serviços básicos, oportunidades de se organizar, participar e ser reconhecido pela sociedade”. E é com esta perspectiva que desenvolve os programas sócioeducativos: "São práticas que promovem novos padrões e referências sociais, norteiam atitudes e comportamentos a partir da convivência, participação e organização" (AMRMC). A Instituição funciona entre $8 \mathrm{~h}$ e $18 \mathrm{~h}$ e conta com equipe técnica (terapeuta ocupacional, psicólogo e educadores), coordenador (assistente social), voluntários, estagiários e parceiros. Aos voluntários têm sido ministrados cursos de capacitação além de supervisão das atividades desenvolvidas.

\section{O censo e a população em situação de rua}

É considerada em situação de rua tanto a pessoa que utiliza os logradouros públicos como locais de habitação e para atividades cotidianas (dormir, alimentar-se e trabalhar) como aquela que pernoita em albergues por não possuir moradia autônoma. Neste estudo foram incluídas as pessoas que utilizam Projetos de Moradia Provisória e outros tipos de moradia precárias (VARANDA, 2003).

Uma reivindicação deste segmento é a inclusão das pessoas em situação de rua no censo brasileiro. Ocorre que, por ter como referência o domicílio, deixa de considerar pessoas que não possuem residência fixa. (VIEIRA et al., 2004, p. 47). A lei 12316/97 pretendeu garantir os direitos de cidadania dessa população. Nela está previsto que "o Executivo deverá até o terceiro ano de gestão realizar o recenseamento da população de rua da Cidade" e nos demais anos de gestão pode caracterizar segmentos específicos, como jovens em situação de rua, entre outros (SÃO PAULO, 2001).

A primeira contagem da população em situação de rua foi realizada em 1991 devido ao trabalho da Prefeitura do Município de São Paulo e de Organizações não governamentais que atuam com esta população. Desde 1991 até hoje, algumas quantificações desta população foram feitas e apesar de terem tido metodologias diferentes, é possível verificar o crescimento desta população na cidade de São Paulo (SAS/FIPE, 2000; VARANDA, 2003), através dos dados divulgados pela SAS/FIPE 2000, conforme pode ser observado no Quadro 1.

Quadro 1 - Levantamento de população em situação de rua em São Paulo, segundo unidades da Secretaria da Assistência Social, logradouros e albergues.

\begin{tabular}{|l|l|l|l|l|l|}
\hline Ano & Cobertura & Unidades de área & Logradouros & Albergue & Total \\
\hline 91 & parcial & 8 regionais SAS & 3392 & - & 1749 \\
94 & município & 17 regionais SAS & 2800 & 1913 & 4549 \\
96 & município & 17 regionais SAS & 3421 & 3416 & 6334 \\
98 & município & 17 regionais SAS & 3037 & 3693 & 8706 \\
2000 & município & 9 distritos censitários & 5013 & 6186 & 10394 \\
2003 & município & 29 distritos censitários & 4208 & \\
\hline
\end{tabular}

\section{Apresentação e discussão dos resultados}

Dentre as 35 pessoas entrevistadas, 30 eram homens e cinco mulheres. A predominância do sexo masculino entre a população em situação de rua na cidade de São Paulo foi constatada na pesquisa realizada pela SAS/Fipe em 2003, mostrando que, entre o total de entrevistados, $84 \%$ são do sexo masculino. 
Em relação à faixa etária, atualizada no final do período da coleta de dados, estabelecemos como parâmetro o intervalo de idade utilizado pela pesquisa SAS-Fipe (2003), os quais podem ser observados no Quadro 2.

Quadro 2 - Comparação da distribuição da faixa etária de frequentadores da AMRMC, segundo a pesquisa SAS/ Fipe (\%) e a pesquisa AMRMC (número absoluto e \%).

\begin{tabular}{|l|l|l|l|}
\hline Idade & AMRMC & AMRMC & SAS/Fipe \\
\hline Menos de 18 & - & - & $2 \%$ \\
$18-25$ & 3 & $9 \%$ & $8 \%$ \\
$26-40$ & 12 & $34 \%$ & $32 \%$ \\
$41-55$ & 17 & $48 \%$ & $35 \%$ \\
+56 & 3 & $9 \%$ & $14 \%$ \\
Não informou & - & - & $9 \%$ \\
Total & 35 & $100 \%$ & $100 \%$ \\
\hline
\end{tabular}

No Quadro 2 os dados da SAS/FIPE (2003) também abrangem faixa etária menor de 18 anos. Isso não ocorre na AMRMC, pois para uma pessoa tornar-se associado da instituição deve ter 18 anos ou mais. Nos dois levantamentos observa-se maior percentual de pessoas entre 26 e 55 anos, sendo que na AMRMC destaca-se maior percentual entre 41 e 55 anos.

Foi pedido aos entrevistados que informassem o tempo que estavam em situação de rua, considerando desde a primeira vez que se encontraram nesta situação. O Gráfico 1 mostra o tempo em que a pessoa referiu estar na rua.

Gráfico 1 - Distribuição (\%) dos freqüentadores da AMRMC segundo tempo de rua.

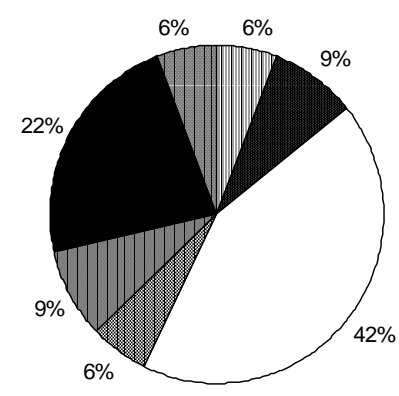

As respostas mostram a heterogeneidade dos entrevistados em relação ao tempo de rua, porém é possível verificar que a grande maioria tem três ou mais anos na situação de rua ( $85 \%$ ) e que temos uma concentração de $42 \%$ pessoas entre 3 e 6 anos e concentração de $22 \%$ de pessoas entre 16 e 25 anos em situação de rua.

O tempo de rua pode revelar diferentes formas de organização para a sobrevivência. Os pesquisadores norteamericanos Snow e Anderson (1998, p. 434) trabalharam com o conceito sociológico de "carreiras" de rua, definidas a partir do tempo e forma de relação que a pessoa estabelece com a rua, buscando mostrar que a condição de desabrigo não é estática, o que pode ser observado em diversos relatos dos entrevistados.

Apesar das pessoas que estão a mais tempo na rua não terem conseguido se desvincular dela e da rede de assistência, temos nos relatos dos entrevistados histórias que mostram uma relação ativa com a vida em busca de soluções para seus problemas e momentos de maior estruturação do cotidiano, como por exemplo, conseguir alugar um quarto de pensão. Dentre as diferenças de tempo em situação de rua observam-se também diferentes histórias de vida. Dentre as pessoas em situação de rua ou socialmente vulneráveis desde a infância, apareceram descrições de situações de maus tratos, trabalho infantil, consumo de álcool na infância, oportunidade de aumento da geração da renda familiar na rua.

\section{Origem e percursos até chegar a AMRMC}

Há uma prevalência entre os entrevistados, de pessoas nascidas no Estado de São Paulo, 19 pessoas, em relação às 16 pessoas nascidas em outros Estados (quatro em Pernambuco, quatro na Bahia, quatro em Minas Gerais, um no Rio de Janeiro e três no Paraná). Estes dados correspondem à pesquisa SAS-FIPE (2000) $)^{(1)}$, identificando a maior concentração de pessoas em situação de rua nascidas no Estado de São Paulo.

Entre os nascidos no Estado de São Paulo, nove nasceram na capital. A partir da questão sobre a trajetória do entrevistado até chegar a AMRMC, foi possível identificar algumas categorias em relação ao processo que a levou à situação de rua:

Dentre os 35 entrevistados: nove nasceram e viveram na Capital e 26 não; sete já chegaram em situação de rua e 16 não; três não informaram. Ainda dentre os entrevistados,

(1) Para algumas comparações será utilizado o relatório de pesquisa SAS/Fipe (2000) por abranger mais dados do que o relatório mais atual de 2003. 
12 saíram da cidade natal e percorreram outras cidades. Algumas narrativas trazem mais detalhes das trajetórias pessoais, mostrando um universo de experiências bastante heterogêneo, como por exemplo: pessoas que nasceram em São Paulo e desde a infância têm contato com a rua, ou que estiveram institucionalizadas na infância (Febem e orfanatos). Algumas pessoas viveram até a fase adulta com a família e narraram problemas de relacionamento familiar e alcoolismo como motivadores da chegada às ruas. Temos relatos de pessoas que vieram a São Paulo para trabalhar e depois que perderam o trabalho chegaram à situação de rua e outros que já chegaram a São Paulo após várias tentativas de se estabelecer em outras cidades, como ilustra a trajetória descrita por JS, um dos entrevistados. JS nasceu na cidade de São Paulo e logo após seu nascimento foi para Pernambuco com sua mãe e um irmão. Ficou lá até os vinte e poucos anos e voltou para São Paulo à procura de melhores oportunidades de trabalho. Morou com parentes e em algumas pensões, variando com as possibilidades financeiras e de convivência. Foi para Holambra (SP), Brasília, retornou para São Paulo e ficou em um albergue próximo a AMRMC começando a freqüentar o serviço. Foi para Belo Horizonte, voltou para São Paulo e novamente para Belo Horizonte. Retornou algumas vezes para Holambra (SP) onde construiu uma rede de apoio importante em uma fazenda em que trabalhou. Em 2002 saiu de Belo Horizonte, passou por Mogi Guaçu (SP), Holambra (SP), Itatiba (SP), Sorocaba (SP), na tentativa de chegar a Curitiba. Não conseguiu passagem e voltou para São Paulo; seguiu para Santo André (SP), ficou cinco dias em um albergue (máximo de tempo permitido) e voltou para São Paulo, procurando o apoio da AMRMC em janeiro de 2003.

Conforme informado, 12 associados afirmaram ter estado em alguma instituição total: sob tutela do Estado FEBEM e orfanatos - (4), presídio (4), FEBEM (2), Hospital psiquiátrico (2) e delegacia (1). Uma pessoa informou ter passagem pelo presídio e FEBEM em relação de conflito com a lei.

A pesquisa SAS de 1991 abordou esta informação e encontrou $20 \%$ dos pesquisados com histórico de internação em alguma instituição, constatando que parece haver um segmento da população em situação de rua procedente de instituições, caracterizado por um grupo jovem (VIEIRA et al., 2004, p.76)

Tipos de moradia, escolaridade, fonte de renda e tempo de permanência na rua e na AMRMC

Embora seja um direito previsto na lei brasileira, a moradia como direito do cidadão está distante de ser uma realidade, principalmente para essa população em situação de desfiliação. O trabalho, a rede relacional e a moradia são constantemente referidos como eixos da ação para a superação das rupturas de participações e do vazio social. Percebe-se, entretanto, que toda abordagem que cinde a atenção em serviços hierarquizados não consegue criar projetos de vida para pessoas singulares, terminando, frequentemente nos limites da abstração. Os tipos de moradia utilizados pelos entrevistados são prova da complexidade da questão: rua, albergues, casas ocupadas, repúblicas. Essas informações podem ser observadas no Gráfico 2.

Gráfico 2 - Distribuição de freqüentadores da AMRMC segundo tipo de lugar em que passam a noite.
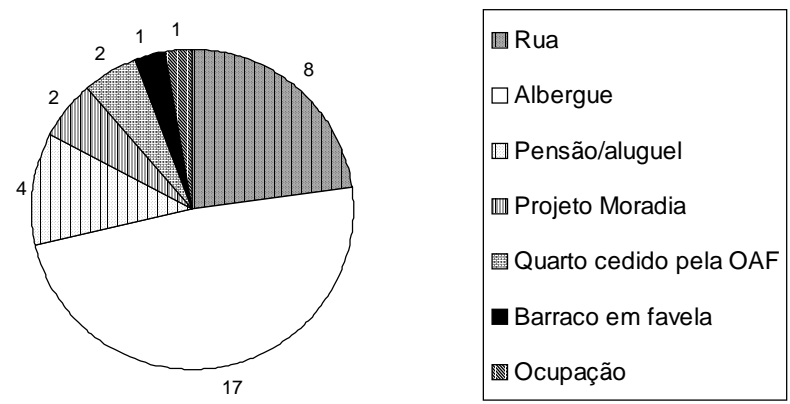

A dimensão temporal desta situação não pode ser observada nestes dados, mas alguns entrevistados informaram já ter estado em diferentes tipos de moradia desde que estão em situação de rua, influenciados por questões que agravam a condição de dormir na rua como o frio e a violência, por exemplo, ou por conseguirem recursos financeiros para uma alternativa. Conforme Viera et al. (2004, p. 79) há uma "uma verdadeira ciranda de alternativas precárias". Albergues e projetos de moradia provisória fazem parte da política de assistência social pensada para esta população na cidade de São Paulo, configurando-se como uma alternativa à rua.

Em 2003 foram encontradas 10394 pessoas em situação de rua na pesquisa SAS-FIPE, 4208 das quais vivendo em logradouros e 6186 em albergues. Nesta pesquisa não foram incluídos os moradores dos projetos de moradia provisória. Os albergues citados pelos entrevistados foram listados depois de corrigidos com base nos dados fornecidos pela SAS e aqueles disponíveis nos endereços eletrônicos das entidades para respeitar o nome oficial, como podemos verificar no Quadro 3. 
GALVANI, D. et al. Perfil dos freqüentadores da casa de convivência. Rev. Ter. Ocup. Univ. São Paulo, v. 17, n. 2, p. 48-56, maio/ago. 2006.

Quadro 3 - Relação de albergues citados e as entidades mantenedoras.

\begin{tabular}{|l|c|l|}
\hline Albergue & Freqüência & \multicolumn{1}{c|}{ Entidade } \\
\hline Assindes & 1 & Servizio Misionário Giovane - SEMIG \\
25 de Janeiro & 1 & Coordenação Regional das Obras de Promoção Humana \\
Estação Vivência & 1 & Coordenação Regional das Obras de Promoção Humana \\
Pousada Cor ação & 2 & Centro de Orientação a Família - COR \\
Dar I & 1 & Coordenação Regional das Obras de Promoção Humana \\
Jacareí & 3 & Sociedade Espírita Medianeiros do Amor \\
Pedro Régis & 1 & Liga das Senhoras Católicas \\
Pedroso & 1 & Associação Metodista de Ação Social - AMAS \\
Reciclázaro Gasômetro & 1 & Associação Reciclázaro \\
São Francisco & 5 & Província Franciscana da Imaculada Conceição \\
\hline
\end{tabular}

Ressalta-se que a maioria dos albergues mencionados é mantida por instituições religiosas além de convênio com a Prefeitura de São Paulo. Esta é uma constante quando se trata de equipamentos sociais voltados para a população em situação de rua. Suas implicações para as vivências desta população poderiam ser avaliadas em uma análise posterior, assim como o aprofundamento do conhecimento das características destes equipamentos e suas particularidades.

Surgiram durante as entrevistas queixas, análises e reflexões sobre os albergues. Rigidez nas regras ou a falta delas, a qualidade dos serviços prestados, assim como estratégias para não ficar sem albergue foram alguns dos temas citados. Observa-se também, através de alguns relatos, que a experiência de frequiência nos albergues varia de acordo com a postura do usuário, principalmente em relação ao seu comportamento. Uma situação diferenciada é a de um entrevistado que freqüenta o albergue e faz trabalhos voluntários no local. Este envolvimento lhe garante a possibilidade de permanecer na instituição por mais tempo do que a média permitida (que é de 3 a 6 meses), além de ter permissão para usar o albergue durante o dia e nos finais de semana.

Entre os entrevistados cinco moram em pensão, quarto alugado ou barraco de favela. Esse fato indica a existência de alguma renda e organização para manter os pagamentos ou mesmo para a construção ou aquisição de um barraco. Esta é a situação destas cinco pessoas entrevistadas, as quais recebem bolsa do projeto de geração de renda "oficina escola" da OAF, está aposentada ou participa da ação coletiva - programa da Prefeitura Municipal de São Paulo.

Estavam dormindo na rua oito pessoas entre os entrevistados e a partir dos seus relatos observam-se diferentes estratégias de sobrevivência em relação à rua. Um deles citou dormir em um mocó o qual descreveu sendo um grupo de pessoas organizadas em função do espaço para dormir. Relatou ser um espaço organizado onde há respeito entre os "moradores". Esta é a situação destas quatro pessoas entrevistadas, as quais trabalham recolhendo e vendendo material reciclável. Observa-se que apenas um dos entrevistados que dorme na rua não faz da coleta uma forma de geração de renda.

Considerou-se igualmente relevante mapear o uso de espaços de referência na cidade e de outros equipamentos sociais. Dos 35 entrevistados, 15 afirmaram utilizar outros recursos e serviços, mostrando que as pessoas buscam ampliar suas referências seja para o lazer, para a formação, para a articulação política seja para a sobrevivência. Nesse sentido, foram referidos:

- Espaços e serviços públicos: Parques (Aclimação, Ibirapuera, da Luz, da Mooca), Centro Cultural Jabaquara, Centro Cultural São Paulo, Projeto Oficina Boracéia;

- Espaços e serviços privados, mantidos por organizações religiosas utilizados para obtenção de serviços: Associação espírita, Igreja Coração de Maria, OAF - Oficina de marcenaria, Casa de Oração do Povo de Rua, Albergue São Francisco (Glicério); 
- Outros espaços e serviços privados com ou sem convênio público: Clube da viola, Casa de Convivência São Martinho de Lima, Centro Social de Integração da Mulher, Mesão;

- Espaços privados: Cine Ipiranga, Estádio do Morumbi.

A busca dos recursos citados revela que o apoio recebido na AMRMC não parece ser percebido como capaz de responder inteiramente às necessidades de seus usuários. Estes, valem-se de recursos múltiplos e diversificados quanto à natureza. Vale ressaltar a busca por capacitação e formação (ensino regular e capacitações para o trabalho): atualização escolar (AMRMC), supletivo - ensino fundamental (Centro Integrado de Educação para Jovens e Adultos - CIEJA), supletivo - ensino médio (CIEJA), aulas de teclado (particular), curso de artesanato (Albergue São Francisco), curso de cabeleireiro (Projeto SASECOP), curso de elétrica (Força Sindical), curso de telemarketing (CIEJA).

Quanto ao grau de escolaridade, observa-se que a grande maioria possui grau de escolaridade baixa: $70 \%$ não concluíram o ensino fundamental (Gráfico 3). Na pesquisa realizada pela SAS em 1991, a maioria das pessoas pesquisadas haviam freqüentado o ensino fundamental sem concluí-lo (VIEIRA et al., 1994, p. 68), o que é semelhante aos dados que encontramos na AMRMC.

Gráfico 3 - Distribuição de freqüentadores da AMRMC segundo grau de escolaridade.
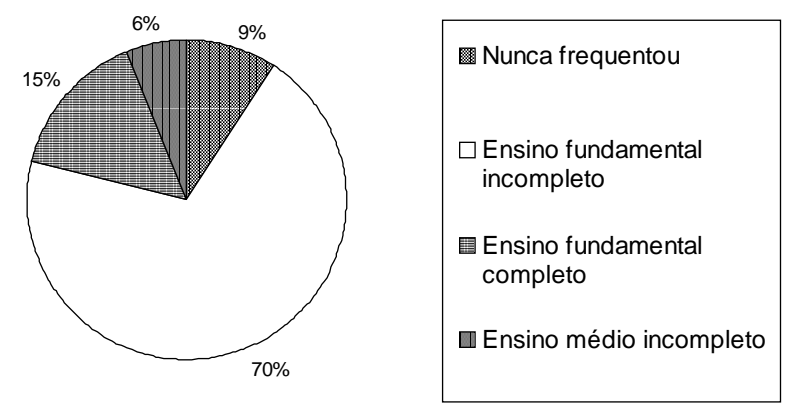

A preocupação com a identificação de possíveis rendimentos por parte dos freqüentadores da AMRMC levou-nos ao mapeamento das suas fontes de renda. Dos 35 entrevistados, 29 afirmaram possuir alguma fonte de renda; $62 \%$ dizem conseguir renda de forma independente da AMRMC e 48\%, por meio de fontes vinculadas aos seus programas de geração de renda. Entre as 22 pessoas que obtêm renda fora da AMRMC, sete pessoas também fazem parte de um dos programas de geração de renda.

Em relação aos 29 entrevistados que possuem renda, 15 estão inseridos em programas da AMRMC.

Quando foram feitas as primeiras entrevistas em 2002, um grupo de associados participava do programa da Prefeitura de São Paulo - Ação coletiva, locados na própria AMRMC e a partir de 2003 um novo grupo foi chamado por este programa.

Em relação ao grupo que citou ter fonte de renda independente da AMRMC esta provém da inserção na rede de assistência através da participação no Projeto Oficina Boracéia (2), na oficina de Marcenaria da OAF (2) e do recebimento de benefícios do Estado (3). Foram encontrados também 13 trabalhadores de mão de obra não especializada que se sujeitam a diferentes "bicos" para gerar renda. Alguns entrevistados informaram que empregadores os procuram no próprio albergue para trabalhar com "bicos" como descarregar caminhão ou trabalhar na construção civil. O Gráfico 4 elucida este perfil.

Gráfico 4 - Freqüentadores da AMRMC segundo tipo de trabalho que realizam independente da AMRMC.

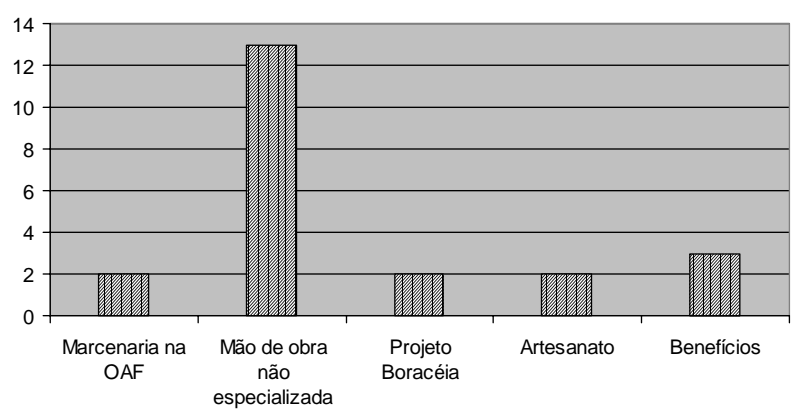

\section{Sobre a AMRMC}

Compreende-se que o dado do tempo em que o entrevistado freqüenta a AMRMC (independente de ter estado associado) deve ser analisado, considerando o tempo em que a pessoa está em situação de rua e sua idade. Observa-se que, com algumas exceções, na faixa etária dos 30 aos 39 anos, concentra-se um maior número de pessoas com mais tempo de rua e de AMRMC. Um grupo expressivo de associados que freqüentam o espaço desde a "época da sopa", preparo e distribuição de sopa realizada anteriormente a existência da AMRMC pela OAF no mesmo local, também foi identificado (Quadro 4). 
GAlVANI, D. et al. Perfil dos freqüentadores da casa de convivência. Rev. Ter. Ocup. Univ. São Paulo, v. 17, n. 2, p. 48-56, maio/ago. 2006.

Quadro 4 - Relação entre tempo de rua e tempo de AMRMC.

\begin{tabular}{|l|c|c|c|c|c|c|c|c|}
\hline $\begin{array}{l}\text { Rua x } \\
\text { associação }\end{array}$ & Menos de 1 & 1 a 2 anos & 3 a 6 anos & $\mathbf{7}$ a 10 anos & 11 a 15 anos & 16 a 25 anos & Mais de 26 anos & Total \\
\hline-1 ano & 2 & 2 & 2 & - & 1 & 3 & & \\
1 a 2 anos & - & 2 & 4 & 1 & - & & \\
Sopa & - & - & - & 1 & 2 & 5 & 2 & \\
3 a 5 anos & - & - & 7 & - & - & 1 & & \\
\hline Total & 2 & 4 & 13 & 2 & 3 & 9 & 2 & 35 \\
\hline
\end{tabular}

\section{CONCLUSÕES}

Os dados do levantamento sobre o perfil dos freqüentadores da AMRMC em São Paulo são semelhantes aos dados SAS/FIPE de 2003. Entretanto, qualificar os associados e usuários permitiu observar uma variedade de trajetórias que recuperam ao centro de convivência e de serviços uma série de possibilidades para (re)tecerem relações, possibilitando trabalhar algum espaço de pertencimento. É preciso restabelecer os lugares da singularidade num contexto de relações que adquirem dinâmicas novas em meio a relações estabelecidas. A pesquisa construída na dialogia acaba por constituir-se em instrumento de mútuo conhecimento o que favorece a continuidade do trabalho.

Compreende-se que o entendimento aprofundado das trajetórias pessoais é imprescindível para que se formulem projetos de vida conjuntamente e de forma orgânica. Esses projetos são processuais e exigem ser repensados a cada passo para ser viável tanto do ponto de vista afetivo como econômico. Todo projeto pessoal de emancipação necessita de uma compreensão das implicações da realidade social na vida cotidiana e os técnicos são operadores sociais que devem trabalhar com base na constituição de vínculos sólidos que só podem ser definidos na relação e no mútuo conhecimento.

Alguns objetivos se repetem como parte de necessidades comuns à população em situação de rua, mas outros são particulares e requerem criatividade e disponibilidade maior por parte dos técnicos. Essa qualidade da atenção é base para atender as necessidades reais e para dialogar com o presente de cada pessoa. A busca de projetos individuais a partir desta rede de relações conduz para a ampliação de redes de apoio, reforçando o que Castel $(1994$, p. 21) denomina de rede de proteção aproximada. $\mathrm{O}$ autor distingue dois registros onde redes de sociabilidade e de solidariedade são tecidas: família e cultura. Neles formam-se espaços e relações de proteção pessoal, social e econômica. A fragilização da família circunscreve uma zona de vulnerabilidade relacional. Suportes afetivos e econômicos cedem lugar a instabilidades relacionais e, frequentemente à solidão e à derrisão. A dimensão da cultura, enquanto constituição do sentimento de pertencimento, maneira de habitar um espaço e de partilhar dos valores, representa outro elemento decisivo na constituição da proteção aproximada.

Neste sentido, a AMRMC, além de ser um centro de referência que permite a satisfação de necessidades de sobrevivência do grupo atendido, busca configurar-se como espaço facilitador e promotor de criação de redes de suporte. O trabalho dos terapeutas ocupacionais do Projeto Metuia na AMRMC constrói-se no diálogo com a Instituição, associados e usuários, tendo em conta a importância de conhecimento aprofundado de cada pessoa, suas histórias, desejos, dificuldades e dinâmicas relacionais e afetivas. Isso, sem esquecer sua dimensão mais coletiva e grupal. Acreditamos que ainda é fundamental realizar ulteriores estudos sobre situações singulares e sobre formas de constituição de possibilidades novas que as pessoas vão desenvolvendo em cotidiano tão adverso.

Ressaltamos assim, a importância da AMRMC no favorecimento de criação de espaços para que as redes relacionais sejam formadas ou fortalecidas. É, igualmente um espaço de negociação cultural e de mediação de conflitos pessoais e grupais. Espaços dessa natureza são necessários, embora insuficientes, para o trabalho com esta população, pois tendem a alavancar as situações de desfiliação (CASTEL, 1994) para outras menos desfavoráveis.

O trabalho da AMRMC com este grupo tem buscado romper os limites da assistência que desconsidera a condição de adultos e sujeitos políticos da população em questão. Infelizmente o número de pessoas atendidas na 
GALVANI, D. et al. Perfil dos freqüentadores da casa de convivência. Rev. Ter. Ocup. Univ. São Paulo, v. 17, n. 2, p. 48-56, maio/ago. 2006.

cidade de São Paulo é demasiado pequeno frente às necessidades e à gravidade da situação - desafio a ser superado a partir de respostas que a própria população poderá produzir.

GALVANI, D.; BARROS, D. D.; SATO, M. T.; REIS, T. A. M.; ALMEIDA, M. C. Profile of users of the center of services "Associação Minha Rua Minha Casa" between 2002 and 2003. Rev. Ter. Ocup. Univ. São Paulo, v. 17, n. 2, p. 48-56, maio/ago. 2006.

\begin{abstract}
This paper discusses the results of a research developed between 2002 and 2003 in the center of services Associação Minha Rua Minha Casa (AMRMC), attendance place to homeless people in the city of São Paulo. Using open and semi-structured interviews, the research aimed to understand the profile of its users, considering the daily trajectories, the characteristics of the circulation in the city of São Paulo and the nets of services and supports used. The data obtained are similar to the data of censuses realized by SAS/FIPE in recent years about this population in the city of São Paulo . However, they reveal different personal trajectories that confer to AMRMC the possibility to create some space of belonging. The deep knowledge of personal trajectories is of essential importance for the creation of personal projects that consider the context and the history of the person cared for. In this perspective, it is intended to work in dialogue with users and institution, understanding that the research is one more instrument in the process of mutual knowledge. The gravity of the situation and the needs of the population impose challenges to be overcome with answers of the own population.
\end{abstract}

KEY WORDS: Vulnerability. Social group. Occupational therapy. Homeless persons. Refuge.

\title{
REFERÊNCIAS
}

AMRMC - Associação Minha Rua Minha Casa. Manual de voluntários. São Paulo, 2003. (mimeografado)

AMRMC - Associação Minha Rua Minha Casa. Presidência de Cláudio Elias Conz. Desenvolvido pela Organização de Auxílio Fraterno e pelo Pensamento Nacional de Bases Empresariais. Disponível em: http://www.minharuaminhacasa.hpg.ig.com.br/ conheca.htm\#conheca. Acesso em: 17 ago. 2005.

CASTEL, R. Da indigência à exclusão, a desfiliação. Precariedade do trabalho e vulnerabilidade relacional. In: LANCETTI, A. (Org.) SaúdeLoucura, n.4. São Paulo: Hucitec, 1994. p. 21-48.

SECRETARIA DE ASSISTÊNCIA SOCIAL (SAS), Fundação Instituto de Pesquisas Econômicas (FIPE). Primeiro censo dos moradores de rua da cidade de São Paulo. São Paulo, 2000.

SECRETARIA DE ASSISTÊNCIA SOCIAL (SAS), Fundação Instituto de Pesquisas Econômicas (FIPE). Estimativa do número de moradores de rua e estudo dos resultados obtidos com o SIS rua. São Paulo, 2003. [Relatório final].
SNOW, D.; ANDERSON, L. Desafortunados: um estudo sobre o povo da rua. Petrópolis: Vozes, 1998.

SÃO PAULO (Município). Decreto regulamentador $n^{\circ} .40 .232$ de 03 de janeiro de 2001. Regulamenta a Lei no 12.316 de 16 de abril de 1997, dispõe sobre a obrigatoriedade do poder público municipal a prestar atendimento à população de rua da cidade de São Paulo, e dá outras providências. Disponível em: http:// www.leismunicipais.com.br/cgi-local/leis2.pl. Acesso em: 16 ago. 2005.

VARANDA, W. Do direito a vida à vida como direito. 2003 Dissertação (Mestrado - Saúde Materno-Infantil) - Faculdade de Saúde Pública, Universidade de São Paulo, São Paulo, 2003.

VIEIRA, M. A. C.; BEZERRA, E. M. R.; ROSA, C. M. M. População de rua: quem é, como vive, como é vista. 3 a ed. São Paulo: Hucitec, 2004. 